\title{
Study of Contemporary College Students' Entrepreneurship Training
}

\author{
Lianxiang LIU \\ Suqian College, Suqian 223800, Jiangsu, China \\ lotusllx@126.com
}

\begin{abstract}
Entrepreneurship is the intrinsic quality of the entrepreneurs and the important requirement for college students to develop entrepreneurship education. To understand and grasp the entrepreneurship has important theoretical and practical significance on cultivating the entrepreneurial spirit and entrepreneurial ability of college students. Based on the cognition, emotion, belief, the unity of meaning, the line Angle, the connotation of entrepreneurship for college students, the present situation and cultivation measures was thinking, to strengthen the consciousness of college students' entrepreneurship and stimulate the entrepreneurial passion, improve college students' creative ability.
\end{abstract}

Index Terms - cultivation; entrepreneurial spirit

\section{Introduction}

College students want to get the success of entrepreneurship, both the need for external environment, but also the need to have their own excellent entrepreneurial spirit. Entrepreneurial spirit is manifested by based on certain entrepreneurial cognition emotion, firm belief, the formation of entrepreneurial motivation, perseverance, indomitable will, perseverance and courage of the entrepreneurial spirit, it governs entrepreneurial attitude and behavior of entrepreneurial activity, whether entrepreneurial spirit pillar. Therefore, from the education source, university should be clear about how college students should have entrepreneurial spirit and quality, and take effective measures to cultivate and improve.

\section{Scientific connotation of College Students Entrepreneurship}

"Spirit", the dictionary definition "refers to people's consciousness, thinking and general mental state". The formation of human spirit. "The fact that in a certain environment condition of the human impact on the intrinsic cognition, emotion, faith and meaning, elements of dialectical movement, balanced development process." [1] Therefore, the entrepreneurial spirit of college students should be composed of five aspects: entrepreneurial knowledge, entrepreneurial emotion, entrepreneurial belief, entrepreneurial will and entrepreneurial behavior.

Entrepreneurial knowledge refers to the college students' connotation of entrepreneurship and related theories, principles, norms and understanding. Cognition is the precursor of behavior. We can see that the entrepreneurial knowledge is the basis and prerequisite for the cultivation of college students' entrepreneurship.
Entrepreneurial emotion refers to the students in the reality of the entrepreneurial performance of interest, love and hate performance. As a kind of non intelligence factor, emotion is the catalyst for understanding and transforming into behavior, and it plays a great adjusting role in human behavior.

Entrepreneurial belief is the sincere faith of a kind of entrepreneurial activity from the bottom of the heart. Certain business cognition, after the human being's reason and the life experience filtered into the belief, only then can become the life struggle guide. Entrepreneurial faith once formed, will make people to pursue the established, loyal through thick and thin never yield in spite of reverses the business objectives.

Entrepreneurial will, refers to the students in the process of entrepreneurial practice, consciously overcome difficulties and overcome obstacles will and perseverance. Will embody the entrepreneurial knowledge and adjust the entrepreneurial behavior of the important spiritual force, is the production of entrepreneurial behavior leverage.

Entrepreneurial behavior is the people in the understanding, emotion, will and faith under the domination of the actual action in practice for entrepreneurship. Entrepreneurial behavior is the external embodiment and comprehensive reflection of a person's entrepreneurial spirit, and the behavior of this behavior is more important to the entrepreneur's entrepreneurial behavior. Rock once said: "only you give him good principles and strong habits, is the best, the most reliable, so is the most should pay attention to. Because all the cautions and rules, however repeated again and again, unless the practice becomes a habit, is not in use." [2]

These five factors are interrelated, mutual infiltration, mutual restriction and mutual promotion in the cultivation of college students' entrepreneurship. Among them, recognition is the premise, emotion and will is the guarantee, faith is the core, behavior is the key.

The cultivation of College Students' entrepreneurial spirit is to sowed the seeds of a grain of start-ups in the hearts of college students, and guide them to entrepreneurship as a future employment so as to realize the value of life in a way, as early as psychologically, knowledge and skills preparation.

\section{Current situation of College Students Entrepreneurship}

\section{A. Lack of entrepreneurial knowledge}

Our survey reveals that there are still a lot of prejudice and lack of students for entrepreneurship. Mainly include: one is narrow, shallow understanding of entrepreneurship, entrepreneurship is the founder of the company, and even the 
work study program is equivalent to the business; second, most of the students think in the business the most critical factor is money, seems to have money is equal to entrepreneurial success, while ignoring the creation spirit and knowledge and skills of the master in the entrepreneurial process and the important role.

\section{B. Entrepreneurial emotion negative}

Nowadays, college students are lack of positive entrepreneurial emotion, is generally believed that entrepreneurship is upset that he "no face" "could not lift their heads", if successful employment, who will bear the pressures of funds, operation and management, labor-intensive businesses and also subjected to pain and test failures and setbacks.

\section{Entrepreneurial beliefs are not firm}

Performance for some of the initial thinking of college students' active, think is their cause, with passion. But in the latter part of the passion missing, especially after suffering setbacks, failure, regret the original why choose to start this road. And some parents in order to enable children to achieve the goal of talents in their ideal, according to their own subjective desire to give their children arrange everything, this excessive doting and arranged makes students lose many dare to think, dare to try daring opportunity, or even with the entrepreneurial idea has finally evaporated.

\section{Entrepreneurial will not strong}

This business is full of difficulties and all sorts of exercise on the road, whether it is resolute and hard entrepreneurial will also is very important, it is students' entrepreneurial behavior can persevere, and ultimately successful key. According to the school where the author of a related survey shows, many university students are in the style of plain living and hard struggle, thrift consciousness, pampered life mentality is very common. There are also the think that hard work is the older generation, contemporary youth do not need to work hard ". Such a state of mind, easily lead to start on the road "business" "do not want to do small things, do not the passive situation, or after the failure of the depressed situation.

\section{E. Lack of entrepreneurial behavior}

In March 2011, according to the "national entrepreneurship research report shows, 80\% were investigators on entrepreneurial interest and think through the self-employed can realize self value and enjoy the freedom of life [3]. And according to Mycos Chinese college students employment research project group to provide the data, from 2007 to 2009 session of the Chinese university graduates proportion of independent entrepreneurs is only $1 \%-1.2 \%$, 2010 session of the Chinese university graduates entrepreneurship ratio than in previous years, although some improvement [4], still far below the average level of other countries in the world. The two different survey results is indeed thought-provoking, on the one hand, college students entrepreneurial interest is very high, nearly $80 \%$ of the college students with strong entrepreneurial intention, on the other hand, Chinese university graduates really entrepreneurship rate is very low, an average of less than $2 \%$. Both internal and external reasons can only explain the fact that the current rate of College Students' self - entrepreneurship is very low, and it is not enough for the practical action. Know, disjointed, lack of practice is today's college students have to face a weak, has become an important factor restricting college students entrepreneurship sailing.

\section{To adhere to the unity of knowledge, affection, faith, intention and behavior, and foster the entrepreneurship of College Students}

A social progress sign does not necessarily mean that a well-known private cars and the popularity of the Internet, it should reflect the members of society in the outlook on life, values, career, view of talent, such as the category of humanities concepts and ways of thinking of updates and changes. Similarly, the essence of entrepreneurship is the formation of entrepreneurial spirit, rather than narrow the entrepreneurial behavior, because once the formation of entrepreneurial spirit, can be implemented in any form, size and nature of the organization.

\section{A. Knowing: establishing the structure of College Students' entrepreneurial knowledge}

The establishment of reasonable structure of knowledge is the primary condition for stimulating college students' entrepreneurship. "I am opposed to college drop out entrepreneurship and Graduate Entrepreneurship behavior, because the knowledge structure of the current university students do not have the conditions of entrepreneurship, even if there is a good idea, is also very easy to be competitors are beating." This is Net ease boss Ding Lei for college students view [5].

University in philosophy of education from "beginner", "Vocational" type of education values turn for the concept of the value of innovation and entrepreneurial education, cultivation of initiative and create innovative talents. The formation of innovation at the same time, the implementation of education and curriculum of mutual penetration of literacy class and professional class, business class, functional complementation of the diversified curriculum system, to broaden the students' knowledge structure to tend to be reasonable and perfect.

\section{B. Passion: inspire students entrepreneurial emotion}

"Good birds greener pastures and" Silicon Valley in the United States is the entrepreneur's paradise ", these two words implied the same truth: loose environment conducive to entrepreneurial consciousness formation and entrepreneurial passion burst. Therefore, the entrepreneurship education in Colleges and universities should create a good entrepreneurial atmosphere for college students, and cultivate their entrepreneurial consciousness and inspire their entrepreneurial spirit. Through extensive entrepreneurial spirit of publicity; start-up celebrities; visit, access and listen to successful entrepreneurship lectures; classic entrepreneurial story of 
appreciation and learning; held pioneering design contest and other activities, to enable students receive education in monasteries, imperceptible.

\section{Firmly believe: the firm belief of College Students}

"Entrepreneurs know more difficult". Any business process cannot do without faith, unremitting self-improvement. Colleges and universities should actively expand the effective ways and methods, especially in Ideological and political theory courses in Colleges and universities, vigorously strengthen the ideal and belief education of college student entrepreneurship and the firm belief for college students' pioneering work, cultivate the entrepreneurial spirit of integrating scientific research, teaching, management and service of the whole process, let students dare to explicitly entrepreneurship as the goal of life, in order to eliminate the business objectives of blank and empty.

\section{Strengthen college students entrepreneurial will}

The difficulties and hardships of greatness. Hard struggle is the indispensable condition for the achievement of entrepreneurship. In order to help students in the firm to do pioneering work independently of willpower, colleges and universities should strengthen the education of the spirit of arduous struggle, to make the youth students fully understand the business of the long-term, arduous and tortuous and make long-term hard work of ideological preparation. Learn to face the venture road on the way to the good times of adversity, strengthen the sense of hardship, be prepared for danger in times of safety awareness, do plain living, thrift, not afraid of difficulties and compatibly, honest business, steadfastly struggle.

\section{E. Heavy behavior: practice college students entrepreneurial behavior}

The long journey takes step by step, the lofty ideal need to realize the struggle of every bit. College students' entrepreneurship is not only a beautiful slogan, but is steadfast, diligent practice, from my start, start from now, and start from the trivial things. Colleges and universities should actively guide students from "empty talk" to "combat training". Therefore, colleges and universities should actively encourage and recommend students to participate in the activities of the college students practice and innovation training project, scientific and technological innovation, entrepreneurial projects competition, which is one of the most effective way of college students during the period of school training innovation ability. Can also organize students into enterprises, factories, rural visit, when conditions are ripe can create students practice base and factories, enterprises, community liaison, regularly organize students in base carry out entrepreneurial practice. While encouraging students the spontaneous formation of the business community, small scale and business practices to try, such as put stall in opening a store or shop etc, for true entrepreneurial experience accumulation and ready to do.

\section{Conclusion}

Entrepreneurship is the intrinsic quality of the entrepreneurs and the important requirement for college students to develop entrepreneurship education. To understand and grasp the entrepreneurship has important theoretical and practical significance on cultivating the entrepreneurial spirit and entrepreneurial ability of college students. Based on the cognition, emotion, belief, the unity of meaning, the line Angle, the connotation of entrepreneurship for college students, the present situation and cultivation measures was thinking, to strengthen the consciousness of college students' entrepreneurship and stimulate the entrepreneurial passion, improve college students' creative ability.

\section{Acknowledgements}

This work was supported by the 2012 Social Science Foundation of Jiangsu Province in China (12MLD011).

\section{References}

[1] Wanbai Chen, Yaocan Zhang, The principle of Ideological and political education, Beijing: Higher Education Press, 2007, pp. 120121

[2] Rock, Christian Education, People's education press, 19857, pp. 30-32

[3] Xinhua, http://news.xinhuanet.com/edu/2011-03/09/c_121168578.htm

[4] Social Sciences Academic Press, (2010)68-72

[5] LeiDing,http://tech.163.com2006-0426,/06/0426/02/2FJQ5UOI000915B2.html

[6] Lianxiang Liu, Thinking about the University Entrepreneurship culture, Chinese University Science and technology and industrialization, vol. 8,no. 10, pp. 35-37, October 2010.

[7] Qihong Hao, The construction of entrepreneurship culture in Chinese colleges and universities, Education exploration, 8 vol, no. 3, pp. 5558, May 2012. 